\title{
MODELING OF SOFTWARE-HARDWARE COMPLEXES
}

\author{
Panel
}

\author{
K. H. (Kane) Kim (Organizer) \\ DREAM Lab., EECS Dept. \\ University of California, Irvine, CA, 92697-2625 USA \\ khkimeuci.edu
}

Various issues related to modeling of software-hardware complexes, including the following, will be addressed.

- Are those currently available modeling approaches insufficient for use in systematic design and optimization of embedded software + hardware systems?

- Are there potential synergies between software modeling and hardware modeling approaches?

- What are the possibilities of and obstacles in combining some software modeling approaches and some hardware modeling approaches?

- What are the kinds of things that software-modeling experts wish to learn from the work on hardware modeling?

The following researchers will serve as panelists:

- Nikil Dutt, UCI, USA

- Hermann Kopetz, Vienna Univ. of Technology, Austria

- Franz Rammig, Univ. of Paderborn, Germany

- Wayne Wolf, Princeton Univ., USA

- Kane Kim, UCI, USA

Position statements of these panelists are in the following. 